"This is a post-peer-review, pre-copyedit version of: Mazzotta F., Sangiorgi C., Vignali V., Lantieri C., Dondi G. (2016) Rheological Characterization of Bituminous Mastics Containing Waste Bleaching Clays. In: Canestrari F., Partl M. (eds) 8th RILEM International Symposium on Testing and Characterization of Sustainable and Innovative Bituminous Materials. RILEM Bookseries, vol 11. Springer, Dordrecht.

The final authenticated version is available online at: https://doi.org/10.1007/97894-017-7342-3_48"

This version is subjected to Springer Nature terms for reuse that can be found at: $h$ ttps://www.springer.com/gp/openaccess/authors-rights/aam-terms-v1 


\title{
Rheological characterization of bituminous mastics containing waste bleaching clays
}

\author{
Francesco Mazzotta ${ }^{a *}$, Cesare Sangiorgi ${ }^{a}$, Valeria Vignalia ${ }^{a}$ Claudio Lantieri ${ }^{a}$, \\ Giulio Dondia \\ a Department of Civil, Chemical, Environmental, and Materials Engineering - DICAM \\ University of Bologna \\ *francesco.mazzotta2@unibo.it
}

\begin{abstract}
Bleaching clays are mostly used in food industries to clarify vegetal oils. After use they are generally dumped as waste (stage 1) or used in green innovative plants to feed biogas reactors (stage 2). In latter stage the initial residual oil content (approx. $25 \%$ by mass) is reduced to less than $1 \%$ by the biological process. In this study the bleaching clays effects on bituminous mastics of a traditional binder course Hot Mix Asphalt have been investigated. The physical characteristics of the two bleaching clays and of a traditional limestone filler were also studied. DSR rheological tests at high and low temperatures were performed on mastics samples containing different amounts of fillers (limestone, stage 1 or stage 2). The addition of the different waste bleaching clays significantly affects the rheological behavior of the mastics: the filler from stage 2 increases the mastic stiffness improving the resistance to permanent deformations as shown by repeated creep tests, while the filler from stage 1 strongly interacts with the bitumen reducing the mechanical characteristics of the mastics at all temperatures.
\end{abstract}

Keywords Bleaching clays, bituminous mastics, Dynamic Shear Rheometer, recycling.

\section{Introduction}

The analysis of the response to load and temperature stresses of the asphalt pavement cannot be separated from the rheological study of the asphalt mastic. The latter, in fact, has a significant impact on the road performance and on the service 
life of the asphalt mixture. Asphalt-filler mastic consists of bitumen and mineral filler that is defined as the portion of aggregates passing the $63 \mu \varepsilon$ sieve (EN 13043 ) and that is generally added to the aggregate mixture during the asphalt mixing process.

Numerous research works show that the mechanical performance of asphalt mastics is largely dependent on fillers properties and on the way they interact with the bitumen (Vignali et al. 2014). This also happens when alternative materials are used instead of common fillers. There are now many studies on scrap and/or waste materials used as fillers in addition or in substitution of raw materials in the production of asphalt concretes (Santagata et al 2014). Sangiorgi et al. (2014) have examined two different types of bentonite clays as replacement of limestone filler for the production of binders course HMAs. The bentonites come from two consecutive industrial processes: spent bentonite (Ut) obtained from a vegetable oil bleaching process (stage 1), and digested spent bentonite (Ud) the result of the anaerobic digestion of spent bentonite within a reactor producing biogas (stage 2). From the analysis of Indirect Tensile Strength and Indirect Tensile Stiffness Modulus data, it was found that the presence of Ut or Ud fillers has a totally different effect on the bituminous mixture's mechanical properties. While digested spent bentonite clay determines an increase in indirect tensile strength and stiffness compared to the mixture with limestone filler, the presence of Ut filler results in an evident reduction of these properties. Besides from the analysis of the dynamic creep test, it was concluded that the substitution of the limestone filler with the Ut filler determines a reduction of resistance to permanent deformations, which is, however, improved using the Ud filler.

Based on these findings the main objective of the present research is to investigate the rheological properties of bituminous mastics containing Ut and Ud fillers, to compare with a traditional mastic containing limestone filler. The mastic stressstrain response is studied through Frequency Sweep (FS), Repeated Creep Recovery (RCR ) and Multiple Stress Creep Recovery (MSCR) tests.

\section{Materials}

In this study three different mastics were produced with a hot mixing process using a 50/70 penetration grade bitumen. The characteristics of the bitumen are shown in Table 1. Three fillers were used: limestone filler, spent bentonite (Ut) and digested spent bentonite (Ud). The following mastics were produced according to the proportions of the AC mixtures studied by Sangiorgi (2014) and summarized in Table 2.

- mastic Mff: 50/70 bitumen with limestone filler;

- mastic MUt: 50/70 bitumen with spent bentonite Ut and limestone filler;

- mastic MUd: 50/70 bitumen with digested bentonite Ud and limestone filler; 
Table 1 Properties of the 50/70 pen bitumen

\begin{tabular}{llll}
\hline & Unit & Characteristic value & Standard \\
\hline Penetration @ $25^{\circ} \mathrm{C}$ & $\mathrm{dmm}$ & $50-70$ & EN 1426 \\
Soft.Point & ${ }^{\circ} \mathrm{C}$ & 50 & EN 1427 \\
Dynamic Visc. $@ 60{ }^{\circ} \mathrm{C}$ & $\mathrm{Pa} \mathrm{s}$ & $\geq 145$ & EN 12596 \\
& ${ }^{\circ} \mathrm{C}$ & -8 & EN 12593 \\
\hline
\end{tabular}

Table 2 Weights percentages of fillers on bitumen

\begin{tabular}{llll}
\hline Mastic & Limestone filler & $\mathrm{Ut}$ & $\mathrm{Ud}$ \\
\hline Mff & $70.6 \%$ & - & - \\
MUt & $41.8 \%$ & $28.8 \%$ & - \\
MUd & $41.8 \%$ & - & $28.8 \%$ \\
\hline
\end{tabular}

\subsection{Fillers from bleaching clay}

Two different bentonite fillers were used in the experimental study obtained from two consecutive phases in the process of bleaching vegetable oils and producing energy from biogas. The filler labelled Ut was derived directly from the bleaching phase (stage 1) and, for this reason, its oil content ranges between $20 \%$ and $25 \%$ of its dry weight. The other filler, Ud, i.e. the digested spent bentonite, is the result of the anaerobic digestion of the Ut filler during the process to produce biogas (stage 2). This phase of biochemical conversion determines a reduction of the content of residual oils, to below $1 \%$.

In order to be used as fillers, both spent bleaching clays were geometrically characterized through a gradation analysis (EN 933-10) and volumetrically, determining their volumetric mass (EN 1097-7) and Rigden Voids (EN 1097-4) (Sangiorgi et al. 2014). Delta Ring \& Ball test was also performed according to EN 13179-1. Table 3 shows the fillers characteristics.

Table 3 Main fillers characteristics

\begin{tabular}{lllll}
\hline & Standard & Limestone filler & Ut filler & Ud filler \\
\hline Particle density $\left(\mathrm{Mg} / \mathrm{m}^{3}\right)$ & EN 1097- & 2.73 & 1.59 & 1.84 \\
Rigden voids $(\%)$ & EN 1097- 4 & 33.82 & 31.69 & 53.75 \\
$\Delta$ Ring \& Ball $\left[{ }^{\circ} \mathrm{C}\right]$ & EN 13179-1 & 8 & -22 & 32 \\
\hline
\end{tabular}




\section{Test method and procedures}

\subsection{Frequency sweep test}

Rheological measurements were performed using a stress/strain controlled Dynamic Shear Rheometer equipped with a parallel plate and plate geometry. The frequency sweep (FS) test was performed in strain control configuration, where the strain amplitude was limited within the linear viscoelastic (LVE) range. Amplitude Sweep (AS) tests were preliminary carried out, to investigate the viscoelasticity region at $10^{\circ} \mathrm{C}$, applying a constant frequency of $10 \mathrm{rad} / \mathrm{s}(1.59 \mathrm{~Hz})$. Linear visco-elastic deformations, $\gamma_{\mathrm{LVE}}$, found for the three mastic were: $1.5 \%$ for Mff, $2.5 \%$ for MUt and $1.0 \%$ for MUd. FS test was conducted in a range of frequencies between 0.01 and $10 \mathrm{~Hz}$, at the temperatures of $0,10,20,30,40,50$ and $60^{\circ} \mathrm{C}$. The $8 \mathrm{~mm}$ plate with a $2 \mathrm{~mm}$ gap was adopted in all the range of temperatures (Dondi et al. 2014). With the FS test the complex shear modulus $\left(\mathrm{G}^{*}\right)$ and the phase angle $(\delta)$ were measured.

\subsection{Repeated Creep Recovery Test}

Repeated Creep Recovery tests (RCR) were conducted with $25 \mathrm{~mm}$ parallel plates (PP) and a $1 \mathrm{~mm}$ gap under three different temperature conditions $46^{\circ} \mathrm{C}, 58^{\circ} \mathrm{C}$ and $64^{\circ} \mathrm{C}$. The testing temperatures were selected in agreement with AASHTO M-320. Mff, MUt and MUd were tested with 100 cycles at a stress level of $1 \mathrm{kPa}$. Each loading cycle consisted of $1 \mathrm{~s}$ creep and $9 \mathrm{~s}$ recovery (NCHRP Report 459). The accumulated strain was calculated for each test at the end of 100 cycles.

\subsection{Multiple Stress Creep Recovery Test}

The Multiple Stress Creep and Recovery test (MSCR) was run according to the AASHTO TP 70-07 “ Standard Method of Test for Multiple Stress Creep and Recovery (MSCR) of Asphalt Binders using a Dynamic Shear Rheometer". According to this standard, mastic sample is loaded at a constant creep stress for $1 \mathrm{~s}$, followed by a zero stress recovery of $9 \mathrm{~s}$. Ten cycles of creep and recovery are run at $0.1 \mathrm{kPa}$ creep stress, followed by ten at $3.2 \mathrm{kPa}$ creep stress. The non-recoverable compliance $\left(\mathrm{J}_{\mathrm{nr}}\right)$ and the percent recovery after ten cycles at $0.1 \mathrm{kPa}$ and $3.2 \mathrm{kPa}$ were studied. The $\mathrm{J}_{\mathrm{nr}}$ value was calculated as the ratio between the average non recoverable strain for 10 creep and recovery cycles, and the applied stress for those cycles. The testing temperatures of $46^{\circ} \mathrm{C}, 58^{\circ} \mathrm{C}$ and $64^{\circ} \mathrm{C}$ were adopted. 


\section{Results and discussion}

\subsection{Frequency sweep test}

The complex modulus $\mathrm{G}^{*}$ and phase angle $\delta$ of mastics MUt, Mff and MUd are represented in terms of master curves in Figure 2. Using the principle of timetemperature superposition (TTS) the master curves of $\mathrm{G}^{*}$ and $\delta$ were plotted at the reference temperature of $20^{\circ} \mathrm{C}$. The Williams-Landel-Ferry model was used to obtain the temperatures shift factors.

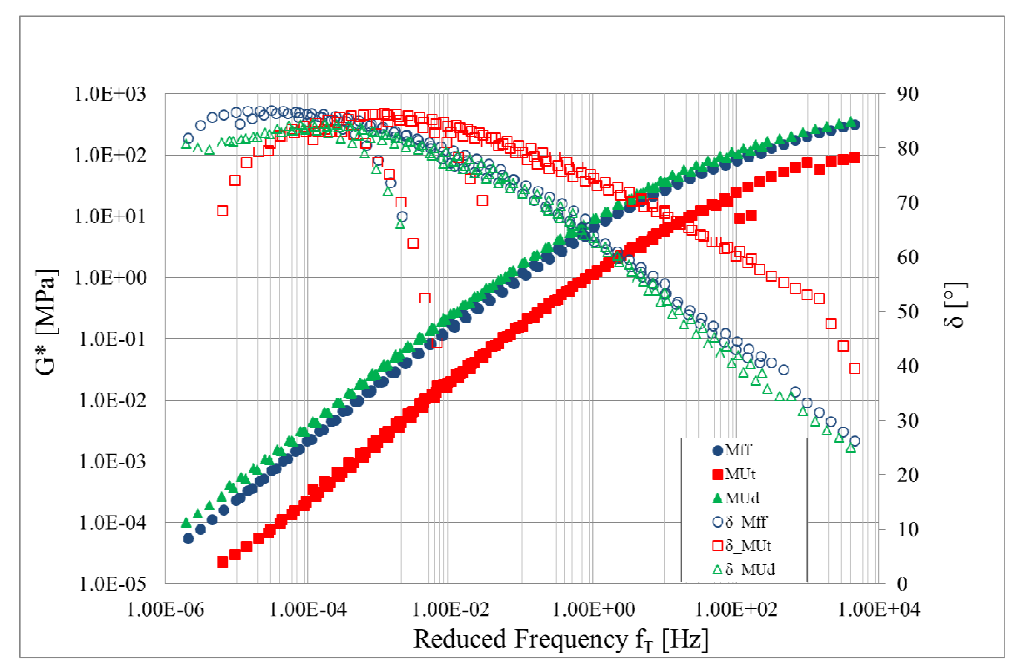

Fig. 2 Master Curves for Mff, MUt, and MUd mastics at $20^{\circ} \mathrm{C}$

Results show that in all range of frequencies the mastic containing the spent bentonite Ut attains $\mathrm{G}^{*}$ values lower than the Mff and MUd mastics ones. Given the nature of the two recycled fillers it can be stated that this difference is mainly due to the different content in residual oil. This is evident at low temperatures or high frequencies where the behavior of the Ut mastic should be dominated by the properties of the base bitumen, but which, in this case, does not tend to the glassy modulus as the Mff and MUd mastics do.

Consistent differences between Mff and MUd mastic can be seen at low frequencies, where the MUd mastic shows higher moduli. It can be inferred that if the presence of filler Ud increases the mastic stiffness at low frequencies it will potentially increase also the resistance to permanent deformations. This can be traced back to the high level of Rigden voids that can demonstrate the stiffening power of the Ud filler (Faheem et al. 2012). 
The mastic containing Ut filler exhibits higher phase angles at medium and high temperatures than Mff and MUd phase angles. At the high temperatures the MUt phase angle decreases, but this effect is significantly far from the one of polymers in polymer modified bitumens. The Mff and MUd $\delta$ values are approximately equivalent at medium and high frequencies, and in particular at high frequencies/low temperatures the mastics response is almost elastic $\left(30^{\circ}\right)$. At high temperatures, on the contrary, the MUd phase angle shows a significant reduction compared to Mff phase angle.

The presence of digested bentonite Ud shifts the rutting parameter $\mathrm{G}^{*} / \mathrm{sen} \delta$ to higher values. This could be seen in Table 3 , in which $\mathrm{G}^{*} / \mathrm{sen} \delta$ values are reported for the three mastics at $60^{\circ} \mathrm{C}$.

Table 3 Rutting parameters of Mff, MUt and MUd

\begin{tabular}{lll}
\hline Mastic & Temperature $\left[{ }^{\circ} \mathrm{C}\right]$ & $\mathrm{G} * / \operatorname{sen} \delta[\mathrm{kPa}]$ \\
\hline Mff & 60 & 7.0 \\
MUt & 60 & 2.5 \\
MUd & 60 & 9.5 \\
\hline
\end{tabular}

\subsection{Repeated Creep Recovery Test}

In order to investigate the materials response to permanent deformations RCR test in plate-plate (PP) configuration were performed at the temperatures of $46^{\circ} \mathrm{C}$, $58^{\circ} \mathrm{C}$ and $64^{\circ} \mathrm{C}$. Figure 3 shows, as an example, the test results at the temperature of $46^{\circ} \mathrm{C}$. In this case, the mastic containing the digested bentonite Ud has accumulated less deformations compared to Mff and MUt that has reached shear strain values close to 100 .

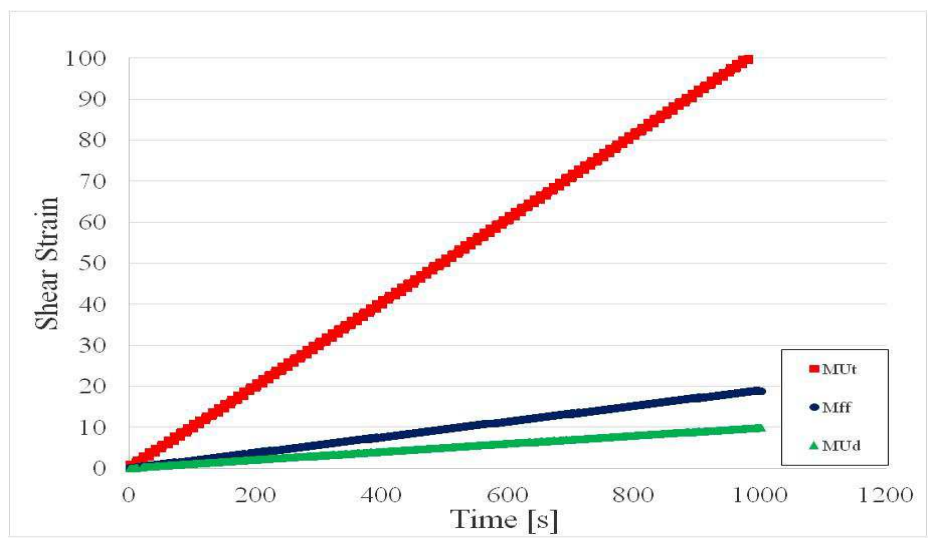

Fig. 4 Results of the accumulated strain under repeated creep testing @ $46^{\circ} \mathrm{C}$. 
Figure 5 shows the test results of the first cycle at $1 \mathrm{kPa}$ at the three test temperatures. The MUt shows considerable higher creep strain at all test conditions. In particular, at $58^{\circ} \mathrm{C}$ the mastic containing the spent bentonite reaches a peak of deformation even higher than the Mff and MUd peaks strain at $64^{\circ} \mathrm{C}$. The MUd mastic shows less sensitivity to deformation in all test conditions.

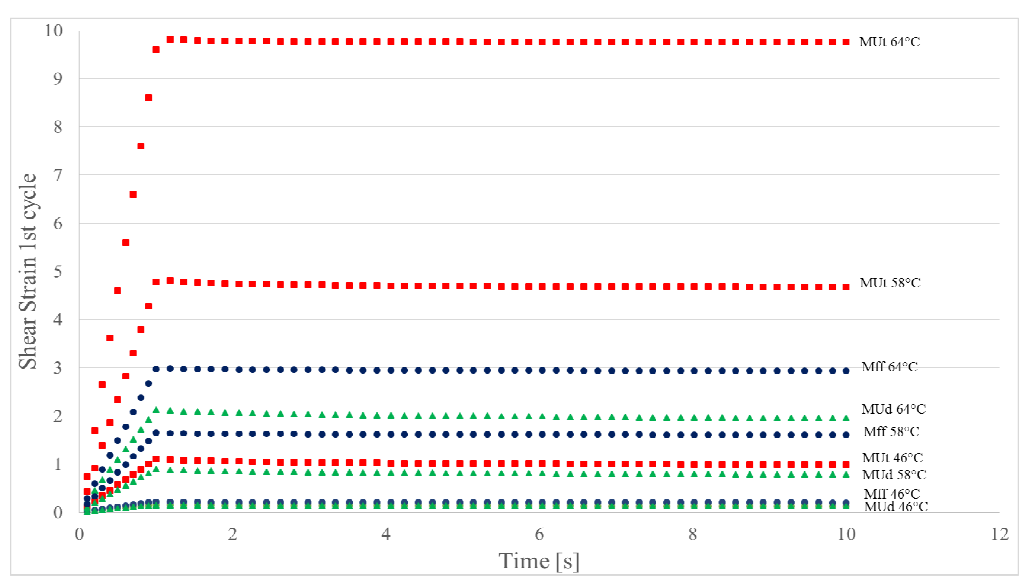

Fig. 5 Strain/time for the first cycle of RCR test at $1 \mathrm{kPa}$ at $46^{\circ} \mathrm{C}, 58^{\circ} \mathrm{C}$ and $64^{\circ} \mathrm{C}$

As shown in Figure 6 this mastics relative behavior is enhanced at the end of the $100^{\text {th }}$ cycle. In fact, MUt has accumulated 461 and 961 strain at $58^{\circ} \mathrm{C}$ and $64^{\circ} \mathrm{C}$ respectively, while Mff and MUd that have reached 75 and 158 strain at $58^{\circ} \mathrm{C}$ and 197 and 295 strain at $64^{\circ} \mathrm{C}$. The accumulated strain difference between the Mff and MUd mastics is close to 10 at $46^{\circ} \mathrm{C}$ and undergoes a significant increase to 96 at the temperature of $58^{\circ} \mathrm{C}$, remaining constant up to $64^{\circ} \mathrm{C}$.

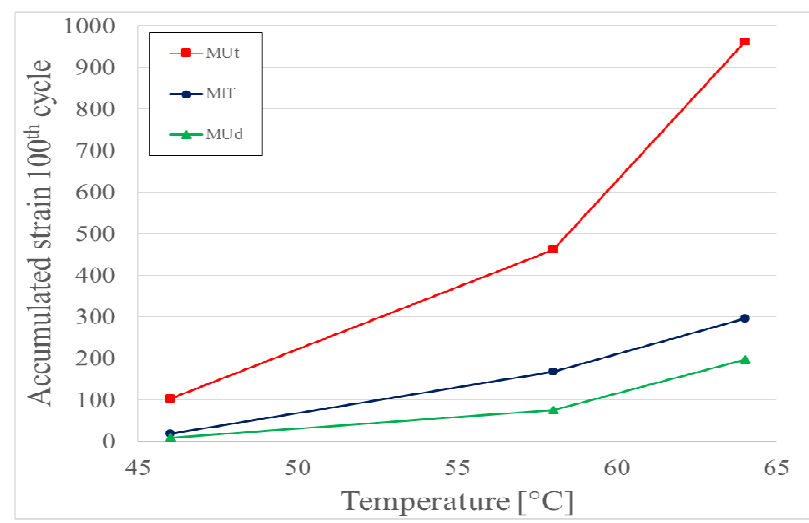

Fig. 6 Accumulated strain values at the end of 100th cycle at $@ 46^{\circ} \mathrm{C}, 58^{\circ} \mathrm{C}$ and $64^{\circ} \mathrm{C}$. 
From this analysis, it is possible to confirm the repeated load axial test results on binder course mixtures presented by Sangiorgi (2014) where the presence of Ud filler used in substitution of the traditional limestone filler decreases the accumulated strain compared to the adopted control mixture.

The percentage of recovery from RCR tests was also obtained and calculated as the ratio between recovered strain and peak strain at the $1^{\text {st }}$ cycle and at the $100^{\text {th }}$ cycle. In Figure 7, the MUd mastic has higher recovery than Mff and MUt at the three test temperatures. Mff and MUt have the same recovery for each test configuration. For MUd there is a constant decrease of $25 \%$ of recovery with increasing temperature than Mff and MUt mastics for which there is a decrease of $80 \%$ of recovery from $46{ }^{\circ} \mathrm{C}$ to $58{ }^{\circ} \mathrm{C}$. At the last load cycle for MUt and Mff mastics the percentage of recovery is 0 at all temperatures. The MUd is the only mastic that shows a small percentage of recovery of $0.3 \%$ at $46^{\circ} \mathrm{C}$ and $0.13 \%$ at $58^{\circ} \mathrm{C}$.

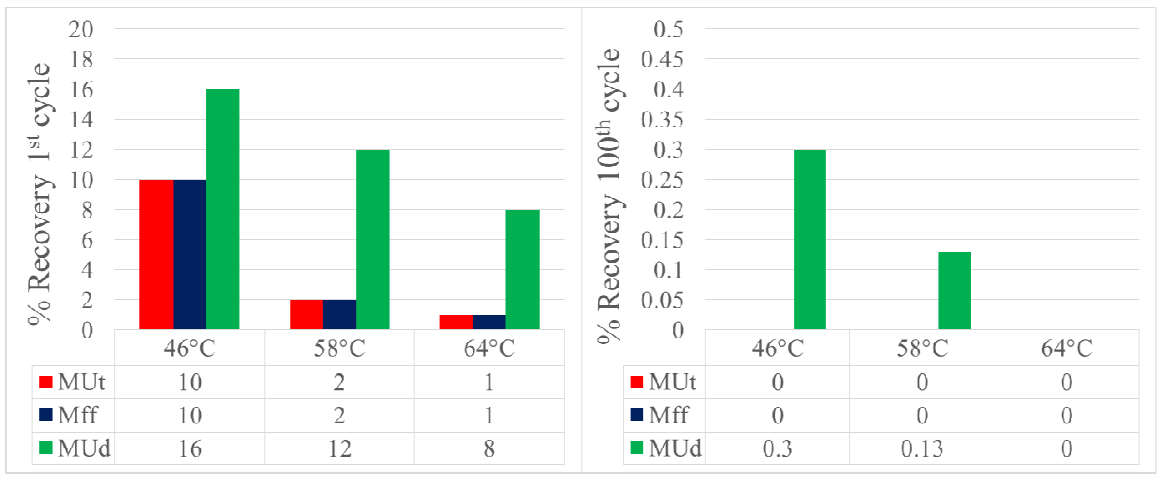

Fig.7 Comparison of RCR \% recovery at the 1 st and 100 th cycle $@ 46^{\circ} \mathrm{C}, 58^{\circ} \mathrm{C}$ and $64^{\circ} \mathrm{C}$.

\subsection{Multiple Stress Creep Recovery Test}

The multiple stress creep-recovery (MSCR) test was developed based on creep studies conduct during the NCHRP 9-10 research program (Bahia \& Hanson 2001). According to the literature (D'Angelo et al. 2007; D'Angelo, 2009b; Wasage et al.2010), this test can predict the deformation behavior of binders. By applying different stress levels, it can identify binders that are overly stress sensitive in the nonlinear region (Soenen et al. 2013). For this reason it was chosen to investigate further the potential rutting of the three mastics Mff, MUt and MUd through MSCR test run at 0.1 and $3.2 \mathrm{kPa}$. Figure 8 shows the test results at the temperature of $46^{\circ} \mathrm{C}$. Also in this test configuration the mastic containing the digested bentonite Ud always exhibits the stiffer behavior, accumulating less deformation at the end of the 10 cycles at $3.2 \mathrm{kPa}$. 


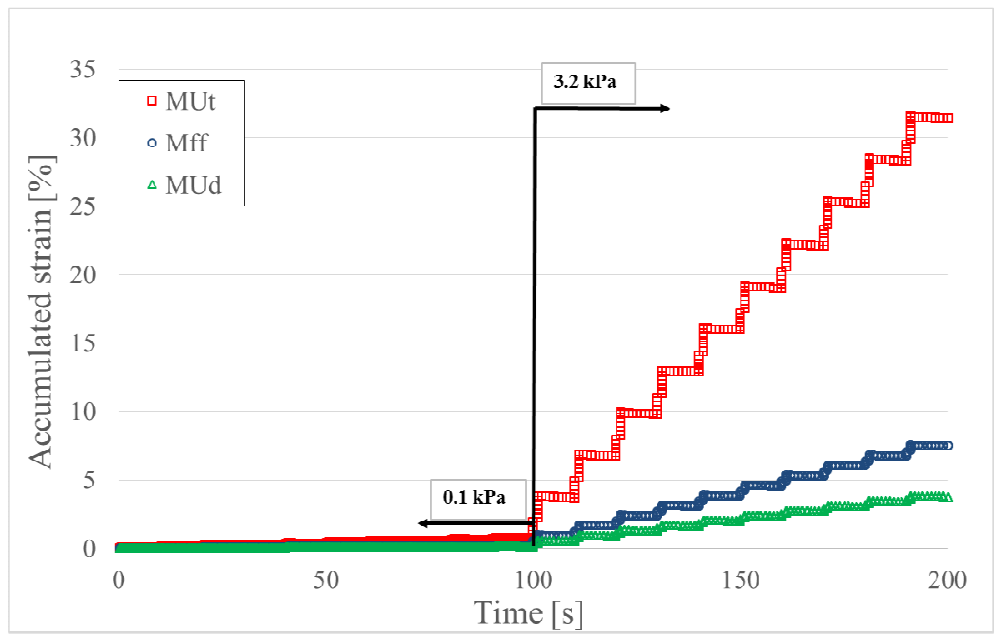

Fig. 8 MSCR test results at $@ 46^{\circ} \mathrm{C}$.

As shown in Figure 9 the mastic MUt has accumulated the largest deformation under the two stress conditions, while the MUd mastic shows the lower values of deformation, even when the temperature increases. For the MUt mastic most part of the strains was developed at the higher stress level.
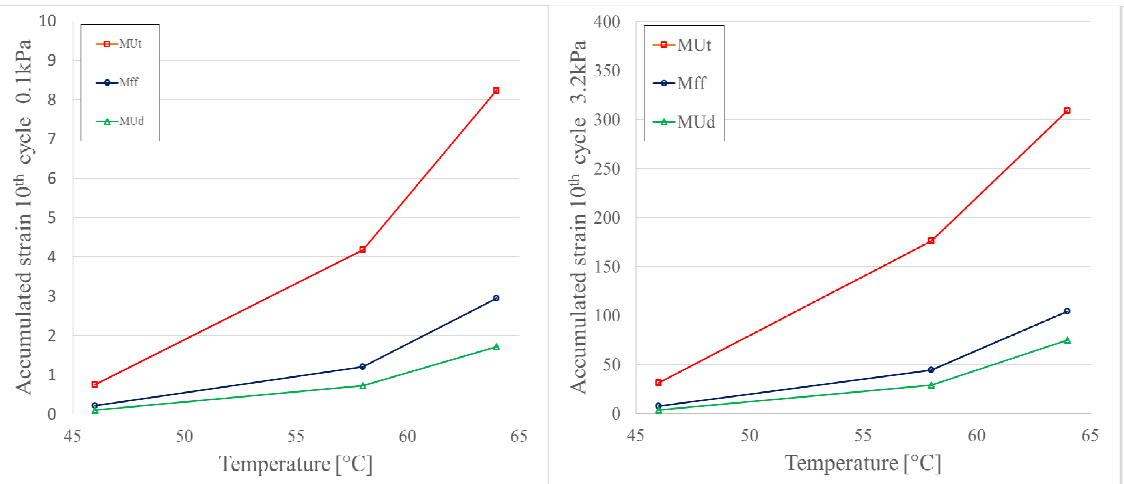

Fig. 9 Accumulated strain values at the end of 10 th cycle at $0.1 \mathrm{kPa}$ and $3.2 \mathrm{kPa}$.

Table 3 shows the average percentage of recovery of the three mastics under 3.2 $\mathrm{kPa}$ shear load at the three test temperatures of $46^{\circ} \mathrm{C}, 58^{\circ} \mathrm{C}$ and $64^{\circ} \mathrm{C}$. At the temperature of $46^{\circ} \mathrm{C}$ the MUd mastic attains an average recovery $\%$ value higher than Mff and MUt; in particular, the average recovery $\%$ of mastic containing digested bentonite reaches $3 \%$. At $58^{\circ} \mathrm{C}$ Mff and MUt do not recover and MUd recovers only the $0.25 \%$ of deformation. At the highest test temperature of $64^{\circ} \mathrm{C}$ all the mastics have no recovery. 
Table 3 Mff, MUt and MUd average percentage of recovery at $3.2 \mathrm{kPa}$

\begin{tabular}{cccc}
\hline & \multicolumn{3}{c}{ Temperature $\left[{ }^{\circ} \mathrm{C}\right]$} \\
\cline { 2 - 4 } Mastic & 46 & 58 & 64 \\
\cline { 2 - 4 } & \multicolumn{4}{c}{ Average \% recovery } & Average $\%$ recovery Average \% recovery \\
\hline Mff & 1.00 & 0 & 0 \\
MUt & 0.42 & 0 & 0 \\
MUd & 3.07 & 0.25 & 0 \\
\hline
\end{tabular}

The creep compliance $\mathrm{J}_{\mathrm{nr}}$ parameter is a measure of the non-recoverable behavior of a binder caused by creep-recovery cycles, and it is therefore suggested to describe the binder contribution to asphalt mixture permanent deformations (D'Angelo et al. 2006). The $\mathrm{J}_{\mathrm{nr}}$ values were calculated for the three mastics under $0.1 \mathrm{kPa}$ (Figure $9 \mathrm{a}$ ) and $3.2 \mathrm{kPa}$ (Figure $9 \mathrm{~b}$ ) shear stresses at the three test temperatures of $46^{\circ} \mathrm{C}, 58^{\circ} \mathrm{C}$ and $64^{\circ} \mathrm{C}$. The MUd mastic has lower values of non recoverable compliance at both shear stresses, showing a less sensitivity of the mastic to permanent deformations. In particular, at $3.2 \mathrm{kPa}$ the mastic containing the $\mathrm{Ud}$ filler shows a $J_{n r}$ value of $13.01 / \mathrm{kPa}$ at $64^{\circ} \mathrm{C}$ while the $\mathrm{J}_{\mathrm{nr}}$ value of mastic containing only limestone filler that is of $18.31 / \mathrm{kPa}$ at the same shear stress and temperature. The MUt mastic has the higher values of $\mathrm{J}_{\mathrm{nr}}$ under all test conditions, it is once again proven that the $25 \%$ of oil in the Ut filler acts on the base bitumen and makes the mastic softer and more susceptible to permanent deformations.
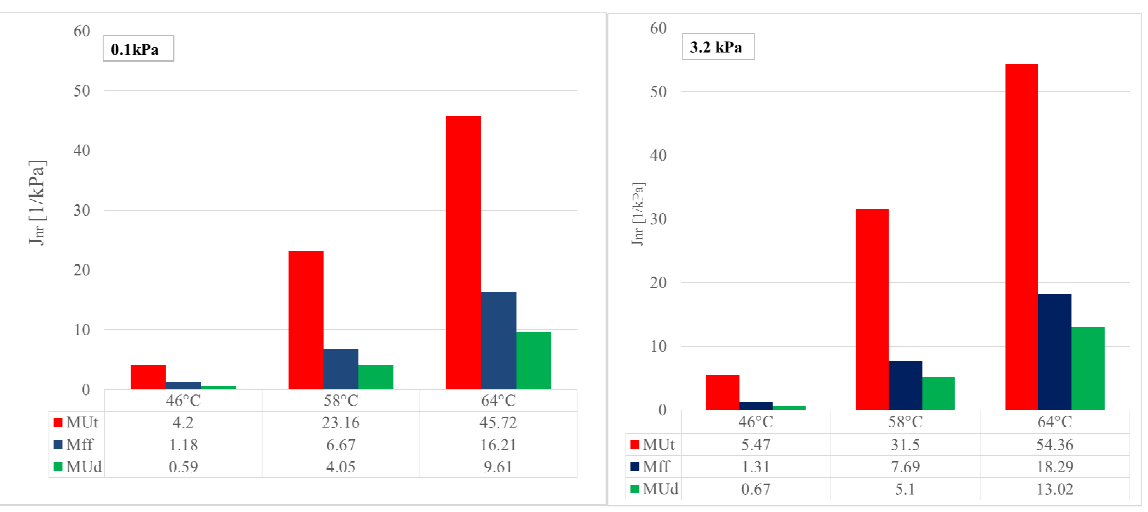

Fig. $9 \mathrm{Mff}$, MUt andMUd non recoverable compliance at $0.1 \mathrm{kPa}$ and $3.2 \mathrm{kPa}$. 


\section{Conclusions}

On the basis of the experimental data presented in this study the following conclusions can be drawn:

- the comparison of the mastics master curves from FS and AS tests show that the substitution of part of the filler in the mixture with the proposed bleaching clays fillers is significantly effective on altering their rheological behavior. Substitutions were made so as to replicate the actual binding mastics of the HMAs tested in previous research. In particular, the study at the mastic scale confirmed that the Ud filler stiffens the base bitumen, while the Ut filler softens the mastic by a considerable amount. Positive aspects with reference to the possible use of mastics in road bituminous pavements are related to the fact that the MUt mastic does not reach the glassy modulus at high frequencies (low temperatures) and that the MUd mastic is stiffer than the Mff mastic at the high temperatures (low frequencies). This is more likely due to the higher value of Ridgen voids of the Ud filler;

- the RCR and MSCR tests results corroborate the repeated load axial test results from previous research on HMAs. The Ut filler reduces the resistance to permanent deformations, while the Ud filler increases it at the different testing temperatures. Also the $\mathrm{J}_{\mathrm{nr}}$ analysis confirms that the non recovered deformations are reduced in the MUd mastic. Again the rheological effect of the Ut filler is more evident in comparison with the traditional mastics containing only limestone filler. The residual oil in the Ut filler is evidently interacting with the bituminous phase more than the mineral particles, thus reversing the effects of the Ud filler;

- the overall rheological analysis confirms that the Ud filler appears to have more positive effects on the mastic of an HMA and this is mainly due to the stiffening power of this digested bleaching clay; nevertheless some positive aspects of the use of Ut filler in mastics can be capitalized on the production of bituminous sealants or membranes were high percentages of fillers are used;

- the presented results are part of a larger study where it is foreseen the optimization of waste bleaching clay fillers volumetrics in the bituminous mixtures. This is to overcome the gradation issues related to the lower particle densities and to take advantage of the high stiffening power of the Ud filler and of the bitumen interaction of the oil in the Ut filler. 


\section{References}

AASHTO M-320. Standard specification for performance - graded asphalt binder.

AASHTO TP 70-07. Standard Method of Test for Multiple Stress Creep Recovery (MSCR) Test of Asphalt Binder Using a Dynamic Shear Rheometer (DSR).

D'Angelo J (2009) The relationship of the MSCR test to rutting. Road Materials and Pavement Design Special Issue, 10: 61-80. doi: 10.3166/RMPD.10HS.61-80

D'Angelo J, Dongre R, Reinke G (2006) Evaluation of repeated creep and recovery test method as analternative to SHRP requirements for polymer modified asphalt binders.

D’Angelo J, Kluttz R, Dongre RN, Stephens K, Zanzotto L (2007) Revision of the Superpave high temperature binder specification: The multiple stress creep recovery test. Association of Asphalt Paving Technologists - Proceedings of the Technical Sessions 76: 293-331.

Dondi G, Vignali V, Pettinari M, Mazzotta F, Simone A, Sangiorgi C (2014) Modeling the DSR complex shear modulus of asphalt binder using 3D discrete element approach. Construction and Building Materials 54: 236-46. doi: 10.1016/j.conbuildmat.2013.12.005

Faheem AF, Hintz C, Bahia H, Al-Qadi I (2012) Influence of filler fractional voids on mastic and mixture performance. Paper presented at the Transportation Research Board Annual Meeting, Washington, D.C., January 22-26.

Sangiorgi C, Tataranni P, Simone A, Vignali V, Lantieri C, Dondi G (2014) Waste bleaching clays as fillers in hot bituminous mixtures. Construction and Building Materials 73: 320-325. doi: 10.1016/j.conbuildmat.2014.09.076

Santagata E, Bassani M, Baglieri O (2014) Use of vitrified municipal solid waste bottom ash as a filler substitute in asphalt mixtures. Sustainability, Eco-Efficiency and Conservation in Transportation Infrastructure Asset Management - Proceedings of the 3rd International Conference on Transportation Infrastructure, ICTI: 15-21. Code 103391

Soenen H, Blomberg T, Pellinen T, Laukkanen O (2013) The multiple stress creep - recovery test: a detailed analysis of repeatability and reproducibility. Road Materials and Pavement Design Vol. 14, No. S1: 2-11. doi: 10.1080/14680629.2013.774742

Transportation Research Board (2001) Characterization of Modified Asphalt Binders in Superpave Mix Design. NCHRP 459.

Vignali V, Mazzotta F, Sangiorgi C, Simone A, Lantieri C, Dondi G (2014) Rheological and 3D DEM characterization of potential rutting of cold bituminous mastics. Construction and Building Materials 73: 339-349. doi: 10.1016/j.conbuildmat.2014.09.051

Wasage T, Stastna J, Zanzotto L (2010) Repeated loading and unloading tests of asphalt binders and mixes. Road Materials and Pavement Design 11: 725-744. doi: 10.3166/RMPD.11.725744 